\title{
Associated factors and prevalence of erectile dysfunction in hemodialysis patients
}

\author{
Márcio Rodrigues Costa, Alexandre Magno Bahia Reis, Bruno Paiva Pereira, Viviane Campos Ponciano, \\ Enio Chaves de Oliveira
}

Division of Urology, Department of Surgery, Hospital das Clinicas, Federal University of Goiás Medical School, Goiânia, Brazil

\section{ABSTRACT}

Purpose: The proposal of this study was to determine the prevalence and the associated factors of erectile dysfunction (ED) among hemodialysis (HD) patients.

Materials and Methods: This was a cross-sectional study based on data collected from HD male patients. Clinical, demographic and laboratory data of all patients were collected in three HD clinics from December 2010 to June 2011. Patients answered questions of erectile function domain from International Index of Erectile Function. Data were evaluated by descriptive analysis and by univariate (ULRA) and multivariate logistic regression analysis (MLRA).

Results: Three hundred and five patients participated of the study. The prevalence of ED was 68.19\%. ED was associated with diabetes (DM), benign prostatic hyperplasia, glomerulonephritis as cause of chronic renal failure (CRF), smoking habits, lower creatinine levels (ULRA), use of calcium channel blocker (MLRA), aging, lower education level, alcohol consumption, DM (as cause of CRF) and coronary insufficiency (ULRA and MLRA).

Conclusions: ED was highly prevalent in the HD men. It was independently associated with aging, current use of alcohol, long alcohol use (even for those who do not drink more), lower education level, diabetes as cause of CRF, coronary insufficiency and use of channel blockers calcium.

\section{ARTICLE INFO}

Key words:

Renal Dialysis; Erectile Dysfunc-

tion; Impotence, Vasculogenic

Int Braz J Urol. 2014; 40: 44-55

Submitted for publication:

January 16, 2013

Accepted after revision:

November 14, 2013

\section{INTRODUCTION}

Erectile dysfunction (ED) is a medical problem that alters patient's quality of life due to association with many problems as anxiety, loss of self-esteem, depression and marital misfit (1). The association of chronic renal failure (CRF) with ED is a well known fact (2). The population of CRF patients in hemodialysis (HD) is growing, in part, because of longer survival (3). This fact has highlighted the importance of quality of life of the HD patients (4), including the erectile function (EF).
The prevalence and determinants of ED are highly variable among HD patients. The determinants are not fully known and the prevalence ranges from 43 to $87 \%$ (5-13). These facts occur due to the lack of standardization of assessment of ED by previous researches (8-10).

In 1997, Rosen et al. reported the International Index of Erectile Function (IIEF) (14). This instrument has been shown to be a cross-culturally and psychometrically valid measurement of male ED. It is a brief, reliable, and valid self-administered questionnaire that standardizes 
ED evaluation and allows the determination of the prevalence of this disorder.

In this study, we aimed to determine the prevalence and the associated factors of ED among HD patients.

\section{MATERIALS AND METHODS}

This was a cross-sectional study based on data collected in three HD centers, from December 2010 to June 2011. The HD centers are not linked or associated with each other or any University; they provide services for patients in the public health system and patients with and without health insurance and perform dialysis of approximately one third of the hemodialysis population of Goiânia, Brazil.

The present study was approved by the Ethics Committee of the Federal University of Goiás Clinical Hospital (under registration $\mathrm{n}^{0}$. 090/2011). Patients included in this work were male voluntary with 18 years of age or older undergoing HD therapy for at least three months. Patients were excluded if they did not complete the EF domain from IIEF, refused to participate in the study, did not sign the consent form or had cognitive or communication impairment.

The six questions of EF domain from IIEF (13) were self answered by each patient during HD sections. This study used the translated Portuguese version of the IIEF. The score for each item ranges from 0 to 5 for questions 1-5 and from 1 to 5 for the question 15. The severities of ED were defined as follows: normal (no ED): 25-30, mild: 19-24, mild to moderate: 13-18, moderate: 7-12, and severe: 1-6 (according to IIEF-1997).

It was considered the diagnosis of comorbidities. Clinical data described in this work were obtained from review of medical records. They included: body mass index (BMI), etiology of CRF, time on HD, presence of hypertension, Diabetes Mellitus (DM), heart or prostate diseases and current medications used.

The following socio demographic variables were collected from each patient in an interview during HD: age, civil status, education level, history of illegal drugs use, cigarettes or alcohol use.
Laboratory parameters were obtained by blood samples at midweek dialysis. These samples were collected up to 30 days before patient's interview. Laboratory data included: creatinine, hemoglobin, hematocrit, triglycerides, low density lipids (LDL)-cholesterol, high density lipids (HDL)-cholesterol, total cholesterol, albumin and parathormone (PTH) levels. To ascertain the adequacy of dialysis prescription for each patient, dialyzer clearance of urea $\mathrm{X}$ dialysis time/volume of distribution of urea (Kt/V) was estimated, using laboratory results gathered from chart review of the previous month to the study.

The data were tabulated on Microsoft ${ }^{\circledR}$ Excel 2007 and evaluated by Statistical Package for the Social Sciences (SPSS) 15 for Windows. A descriptive analysis of score of EF domain from IIEF and of the clinical, socio demographic and laboratory data from all patients was carried out. Continuous variables were divided into categories to facilitate analysis (categorical variable). All variables were evaluated by the proportion in each category. The univariate logistic regression analysis (ULRA) was performed on the EF domain from IIEF versus clinical, socio demographic and laboratory data. Those variables in which the ULRA had a $P$ value less than 0.1 were considered for inclusion in multivariable logistic regression analysis (MLRA). Results were expressed as adjusted odds ratios and their 95\% confidence interval. Statistical significance was set at $\mathrm{P}<$ 0.05 in all analysis.

\section{RESULTS}

Among 349 eligible patients, 305 (87.39\%) participated of this study. Forty-four $(12.60 \%)$ patients were excluded, 29 (8.30\%) did not complete the EF domain from IIEF, 7 (2.00\%) refused to take part of the study, 3 (0.85\%) refused to sign a declaration of informed consent and 5 (1.43\%) had cognitive or communication deficits. The mean \pm SD age was $54.09 \pm 13.17$ years, the schooling time was $7.41 \pm 4.60$ years and the HD time was $50.65 \pm 41.15$ months. The underlying etiologies of renal failure of the patients who participated in the study included hypertension (34.42\%), Diabetes Mellitus (18.36\%), 
glomerulonephritis (7.54\%), polycystic kidney (5.24\%), abuse of medications (3.93\%), unknown (24.59\%) and others (5.57\%).

The prevalence of ED was 68.19\%. The degree of ED among HD patients was mild in $9.83 \%$, mild to moderate in $6.22 \%$, moderate in 9.18\%, and severe in $42.95 \%$ of patients. Among HD patients with ED, $11(5.88 \%)$ received some type of treatment. Nine (4.82\%) used oral drugs, 1 $(0.53 \%)$ intracavernosal drugs and $1(0.53 \%)$ patient received a penile prosthesis.

Most patients (81.31\%) were using some antihypertensive. Despite this no antihypertensive drugs (diuretics, adrenergic inhibitors, direct vasodilators, calcium channel blockers, angiotensin converting enzyme inhibitors, angiotensin receptor blockers 1 and direct renin inhibitors) or other medications (erythropoietin, anxiolytic, anticonvulsant and antidepressant) were found to increase the probability of ED on ULRA.

ED was associated with, aging, lower education level (Table-1), history of cigarette use pre- vious or current, duration of smoking (smoking or smoked), being an ex-smoker, higher pack-year index, pattern of high consumption of cigarettes (current or previous) (Table-2), history of alcohol consumption (current and past) current alcohol consumption, longer alcohol consumption (current or previous) (Table-3), the presence of diabetes (regardless of being or not the cause of the CRF), BPH or coronary insufficiency (Table-4), lower creatinine levels (Table-5), DM and glomerulonephritis (as underlying etiologies of renal failure) (Table-6) on ULRA.

Hypertension, history of drug use (previous or current), use of calcium channel blockers or adrenergic inhibitors had P between 0.05 and 0.10 on ULRA, therefore, these variable was assessed by MLRA.

ED was independently associated with aging, current use of alcohol, long alcohol use (even for those who do not drink anymore), lower education level, DM (as cause of CRF), coronary insufficiency and use of channel blockers calcium (Table-7). The aging, DM (as cause of CRF), and

Table 1 - Association of socio demographic data with Erectile Dysfunction in hemodialysis patients.

\begin{tabular}{|c|c|c|c|c|c|c|}
\hline \multirow[t]{2}{*}{ Socio demographic data } & \multicolumn{2}{|c|}{ Without ED } & \multicolumn{2}{|c|}{ With ED } & \multirow[t]{2}{*}{ P-values* } & \multirow[t]{2}{*}{ OR $(95 \% \mathrm{Cl})$} \\
\hline & $\mathrm{n}$ & $\%$ & $\mathrm{n}$ & $\%$ & & \\
\hline \multicolumn{7}{|l|}{ Age (years) } \\
\hline$<50$ & 64 & 66.0 & 49 & 23.6 & & \\
\hline$\geq 50$ & 33 & 34.0 & 159 & 76.4 & $<0.001$ & $6.293(3.711-10.672)$ \\
\hline \multicolumn{7}{|l|}{ Marital status } \\
\hline Single & 28 & 28.9 & 65 & 31.3 & & \\
\hline Married & 69 & 71.1 & 143 & 68.8 & 0.674 & \\
\hline \multicolumn{7}{|l|}{ Body mass index } \\
\hline$<25$ & 65 & 67.0 & 137 & 65.9 & & \\
\hline$\geq 25$ & 32 & 33.0 & 71 & 34.1 & 0.844 & \\
\hline \multicolumn{7}{|l|}{ Educational level } \\
\hline Incomplete elementary education & 47 & 48.5 & 133 & 63.9 & & \\
\hline Elementary school or up graduate & 50 & 51.5 & 75 & 36.1 & 0.011 & $1.89(1.16-3.07)$ \\
\hline
\end{tabular}

*Estimated by univariate logistic regression analysis; $\mathbf{E D}=$ Erectile Dysfunction; $\mathbf{O R}=$ odds ratio;

$\mathbf{P}=$ Statistical significance; $\mathbf{9 5} \% \mathbf{C l}=95 \%$ confidence interval. 
Table 2 - Association of smoking habits with Erectile Dysfunction in hemodialysis patients.

\begin{tabular}{|c|c|c|c|c|c|c|}
\hline \multirow[t]{2}{*}{ Smoking habits } & \multicolumn{2}{|c|}{ Without ED } & \multicolumn{2}{|c|}{ With ED } & \multirow[t]{2}{*}{ P-values* } & \multirow[t]{2}{*}{ OR $(95 \% \mathrm{CI})$} \\
\hline & $\mathrm{n}$ & $\%$ & $\mathrm{n}$ & $\%$ & & \\
\hline
\end{tabular}

History of current or previous smoking

\begin{tabular}{|c|c|c|c|c|c|c|}
\hline No & 54 & 55.7 & 85 & 40.9 & & \\
\hline Yes & 43 & 44.3 & 123 & 59.1 & 0.016 & $1.82(1.12-2.96)$ \\
\hline
\end{tabular}

Active smoker

$\begin{array}{lllllll}\text { No } & 86 & 88.7 & 187 & 89.9 & & \\ \text { Yes } & 11 & 11.3 & 21 & 10.1 & 0.741 & 0.88(0.41-1.90)\end{array}$

Former smoker

$\begin{array}{lllllll}\text { No } & 65 & 67.0 & 106 & 51.0 & & \\ \text { Yes } & 32 & 33.0 & 102 & 49.0 & 0.009 & 1.95(1.18-3.23)\end{array}$

Nonsmokers ${ }^{c}$

\begin{tabular}{|c|c|c|c|c|c|c|}
\hline No & 43 & 44.3 & 123 & 59.1 & & \\
\hline Yes & 54 & 55.7 & 85 & 40.9 & 0.016 & $1.82(1.12-2.96)$ \\
\hline
\end{tabular}

Pattern of current cigarette smoking (smokers)

$\begin{array}{lcccccc}\text { Light }^{\mathrm{d}} & 7 & 63.6 & 14 & 70.0 & & \\ \text { Moderate }^{\mathrm{e}} & 3 & 27.3 & 5 & 25.0 & & \\ \text { Heavy }^{\dagger} & 1 & 9.1 & 1 & 5.0 & 0.647 & 0.76(0.23-2.49)\end{array}$

Pattern of current cigarette smoking

(smokers and former smokers)

$\begin{array}{lllllll}\text { Light }^{\mathrm{d}} & 23 & 53.5 & 43 & 35.5 & & \\ \text { Moderate }^{\mathrm{e}} & 12 & 27.9 & 42 & 34.7 & & \\ \text { Heavy }^{\dagger} & 8 & 18.6 & 36 & 29.8 & 0.045 & 1.59(1.01-2.51)\end{array}$

Years of smoking (smoking or smoked)

$\begin{array}{lllllll}<20 & 22 & 51.2 & 32 & 26.2 & & \\ \geq 20 & 21 & 48.8 & 90 & 73.8 & 0.003 & 2.95(1.43-6.06)\end{array}$

\section{Pack-year index}

$\begin{array}{lllllll}<20 & 30 & 69.8 & 56 & 46.3 & & \\ \geq 20 & 13 & 30.2 & 65 & 53.7 & 0.009 & 2.68(1.27-5.63)\end{array}$

*Estimated by univariate logistic regression analysis; aSmoked more than 100 cigarettes and currently smoke; bSmoked or had smoked up to 100 cigarettes and currently do not smoke; 'Smoked or had smoked a maximum of 100 cigarettes and currently do not smoke; dSmoked more than 100 cigarettes and currently or previously smokes up to 10 cigarettes / day; 'eSmoked more than 100 cigarettes and currently or previously smokes 10 to 20 cigarettes / day; 'SToked more than 100 cigarettes and currently or previously smokes more than 20 cigarettes / day; $\mathbf{E D}=$ Erectile Dysfunction; $\mathbf{O R}=$ 0dds ratio; $\mathbf{P}=$ Statistical significance; $\mathbf{9 5 \%} \mathbf{C l}$ = 95\% confidence interval. 
Table 3 - Association of habit of use of alcohol and drugs with Erectile Dysfunction in hemodialysis patients.

\begin{tabular}{llclll}
\hline Parameters & \multicolumn{2}{c}{ Without ED } & With ED & P-values* & OR (95\% CI) \\
\cline { 2 - 4 } & $\mathrm{n}$ & $\%$ & $\mathrm{n}$ & $\%$ \\
\hline
\end{tabular}

History of alcohol use current or previous

$\begin{array}{lcccccc}\text { No } & 12 & 12.4 & 51 & 24.5 & & \\ \text { Yes } & 85 & 87.6 & 157 & 75.5 & 0.017 & 2.30 \text { (1.16- 4.55) } \\ \text { rent use of alcohol } & \text { a } \\ \text { No } & & & & & & \\ \text { Yes } & 70 & 72.2 & 182 & 87.5 & & \\ & 27 & 27.8 & 26 & 12.5 & 0.001 & 2.70(1.47-4.94)\end{array}$

Former user of alcohol ${ }^{b}$

$\begin{array}{lllllll}\text { No } & 39 & 40.2 & 77 & 37.0 & & \\ \text { Yes } & 58 & 59.8 & 131 & 63.0 & 0.593 & 1.14(0.70-1.87)\end{array}$

Never used alcohol ${ }^{\mathrm{c}}$

$\begin{array}{lllllll}\text { No } & 85 & 87.6 & 157 & 75.5 & & \\ \text { Yes } & 12 & 12.4 & 51 & 24.5 & 0.017 & 2.30 \text { (1.16-4.55) }\end{array}$

Pattern of alcohol consumption (current alcohol user)

Moderate $^{d}$
Excessive $^{\mathrm{e}}$
tern of alcohol consumption (former and
rent alcohol users)

$\begin{array}{lllllll}\text { Moderate }^{d} & 37 & 43.5 & 66 & 41.8 & & \\ \text { Excessive }^{\mathrm{e}} & 48 & 56.5 & 92 & 58.2 & 0.792 & 1.07(0.63-1.83)\end{array}$

Years use of alcohol (even if already not drink any more)

$\begin{array}{lrrrrrr}<20 & 42 & 49.4 & 45 & 28.7 & & \\ \geq 20 & 43 & 50.6 & 112 & 71.3 & 0.001 & 2.43(1.41-4.21) \\ \text { No } & & & & & & \\ \text { Yes } & 85 & 87.6 & 196 & 94.2 & \\ & 12 & 12.4 & 12 & 5.8 & 0.051\end{array}$

*Estimated by univariate logistic regression analysis; ' $\mathrm{C}$ Currently use alcohol regularly; ${ }^{\mathrm{b} C u r r e n t l y ~ d o e s ~ n o t ~ u s e ~ a l c o h o l ~ b u t ~ h a d ~ a l r e a d y ~ r e g u l a r l y ~ u s e d ; ~} \mathrm{c}$ Never used alcohol. dRegular or previously use of alcohol up to 2 doses ( $350 \mathrm{~mL}$ of beer or $150 \mathrm{~mL}$ of wine or $50 \mathrm{~mL}$ of distilled) / day; e Regular or previously use of alcohol, 5 doses / occasion or more / at least 1 time / week or three or more doses daily;

ED = Erectile Dysfunction; $\mathbf{O R}=$ 0dds ratio; $\mathbf{P}=$ Statistical significance; $\mathbf{9 5} \% \mathbf{C I}=95 \%$ confidence interval. 
Table 4 - Association of clinical data with Erectile Dysfunction in hemodialysis patients.

\begin{tabular}{|c|c|c|c|c|c|c|}
\hline \multirow[t]{2}{*}{ Clinical data } & \multicolumn{2}{|c|}{ Without ED } & \multicolumn{2}{|c|}{ With ED } & \multirow[t]{2}{*}{ P-values* } & \multirow[t]{2}{*}{$\mathrm{OR}(95 \% \mathrm{Cl})$} \\
\hline & $\mathrm{n}$ & $\%$ & $\mathrm{n}$ & $\%$ & & \\
\hline \multicolumn{7}{|l|}{ Diabetes } \\
\hline No & 88 & 90.7 & 126 & 60.6 & & \\
\hline Yes & 9 & 9.3 & 82 & 39.4 & $<0.001$ & $6.363(3.036-13.339)$ \\
\hline \multicolumn{7}{|l|}{ Hypertension } \\
\hline No & 21 & 21.6 & 51 & 24.5 & & \\
\hline Yes & 76 & 78.4 & 157 & 75.5 & 0.583 & \\
\hline \multicolumn{7}{|c|}{ Cardiac arrhythmia } \\
\hline No & 95 & 97.9 & 196.0 & 94.2 & & \\
\hline Yes & 2 & 2.1 & 12.0 & 5.8 & 0.168 & \\
\hline \multicolumn{7}{|c|}{ Coronary insufficiency } \\
\hline No & 96 & 99.0 & 180.0 & 86.5 & & \\
\hline Yes & 1 & 1.0 & 28.0 & 13.5 & 0.008 & $14.93(2.00-111.45)$ \\
\hline \multicolumn{7}{|c|}{ Congestive heart failure } \\
\hline No & 95 & 97.9 & 199 & 95.7 & & \\
\hline Yes & 2 & 2.1 & 9 & 4.3 & 0.334 & \\
\hline \multicolumn{7}{|c|}{ Cardiac valvulopathy } \\
\hline No & 97 & 100.0 & 204 & 98.1 & & \\
\hline Yes & 0 & 0.0 & 4 & 1.9 & & \\
\hline \multicolumn{7}{|c|}{ Other heart diseases } \\
\hline No & 95 & 97.9 & 195 & 93.8 & & \\
\hline Yes & 2 & 2.1 & 13 & 6.3 & 0.134 & \\
\hline \multicolumn{7}{|c|}{ Benign prostatic hyperplasia } \\
\hline No & 95 & 97.9 & 179 & 86.1 & & \\
\hline Yes & 2 & 2.1 & 29 & 13.9 & 0.006 & $7.70(1.80-32.95)$ \\
\hline \multicolumn{7}{|c|}{ Prostate cancer } \\
\hline No & 97 & 100.0 & 206 & 99.0 & & \\
\hline Yes & 0 & 0.0 & 2 & 1.0 & & \\
\hline \multicolumn{7}{|c|}{ Time on hemodialysis (months) } \\
\hline$<48$ & 50 & 52.1 & 122 & 59.2 & & \\
\hline$\geq 48$ & 46 & 47.9 & 84 & 40.8 & 0.244 & \\
\hline \multicolumn{7}{|c|}{$\begin{array}{l}\text { Long of diagnosis of chronic renal } \\
\text { failure(months) }\end{array}$} \\
\hline$<48$ & 38 & 39.6 & 88 & 42.9 & & \\
\hline$\geq 48$ & 58 & 60.4 & 117 & 57.1 & 0.584 & \\
\hline
\end{tabular}

*Estimated by univariate logistic regression analysis; $\mathbf{E D}=$ Erectile Dysfunction; $\mathbf{H D}=$ hemodialysis; $\mathbf{O R}=$ Odds ratio; $\mathbf{P}=$ Statistical significance; $\mathbf{9 5 \%} \mathbf{C l}=95 \%$ confidence interval. 
Table 5 - Association of laboratory values and Erectile Dysfunction in hemodialysis patients.

\begin{tabular}{|c|c|c|c|c|}
\hline \multirow[t]{2}{*}{ Laboratory parameters } & Without ED & With ED & P-values* & OR $(95 \% \mathrm{Cl})$ \\
\hline & $\%$ & $\%$ & & \\
\hline
\end{tabular}

Hemoglobin $(g / d L)$

$\begin{array}{lccccc}<10 & 24 & 24.7 & 51 & 24.5 & \\ \geq 10 & 73 & 75.3 & 157 & 75.5 & 0.966\end{array}$

Hematocrit (\%)

$\begin{array}{llllll}<30 & 22 & 22.7 & 48 & 23.1 & \\ \geq 30 & 75 & 77.3 & 160 & 76.9 & 0.939\end{array}$

Albumin $(\mathrm{g} / \mathbf{1 0 0 \mathrm { mL } )}$

$\begin{array}{lccccc}<3.5 & 3 & 3.1 & 9 & 4.4 & \\ \geq 3.5 & 93 & 96.9 & 195 & 95.6 & 0.598\end{array}$

Cholesterol (mg/dL)

$\begin{array}{llllll}<200 & 75 & 78.1 & 150 & 75.4 & \\ \geq 200 & 21 & 21.9 & 49 & 24.6 & 0.603\end{array}$

Cholesterol LDL (mg/dL)

$\begin{array}{llllll}<130 & 84 & 89.4 & 170 & 87.6 & \\ \geq 130 & 10 & 10.6 & 24 & 12.4 & 0.669\end{array}$

Cholesterol HDL (mg/dL)

$\begin{array}{lccccc}<40 & 48 & 50.0 & 88 & 44.4 & \\ \geq 40 & 48 & 50.0 & 110 & 55.6 & 0.371\end{array}$

Triglycerides (mg/dL)

$\begin{array}{llllll}<150 & 47 & 49.0 & 85 & 42.7 & \\ \geq 150 & 49 & 51.0 & 114 & 57.3 & 0.313\end{array}$

Creatinine (mg/dL)

$\begin{array}{lllllll}<8 & 15 & 15.5 & 66 & 31.7 & & \\ \geq 8 & 82 & 84.5 & 142 & 68.3 & 0.003 & 0.394(0.211-0.734)\end{array}$

Parathormone $(\mathrm{pg} / \mathrm{mL})$

$\begin{array}{llllll}<300 & 42 & 43.3 & 109 & 52.7 & \\ \geq 300 & 55 & 56.7 & 98 & 47.3 & 0.129\end{array}$

$\mathrm{Kt} / \mathrm{V}$

$\begin{array}{lccccc}<1.2 & 21 & 21.6 & 34 & 16.7 & \\ \geq 1.2 & 76 & 78.4 & 170 & 83.3 & 0.297\end{array}$

*Estimated by univariate logistic regression analysis; $\mathbf{E D}=$ Erectile dysfunction; $\mathbf{H D L}=$ High density lipids; $\mathbf{K t} / \mathbf{V}=$ Dialyzer clearance of urea X dialysis time/volume of distribution of urea; LDL = Low density lipids; $\mathbf{O R}=$ Odds ratio; $\mathbf{P}=$ Statistical significance; $\mathbf{9 5} \% \mathbf{C l}=95 \%$ confidence interval. 
Table 6 - Association of cause of chronic renal failure with Erectile Dysfunction in hemodialysis patients.

\begin{tabular}{|c|c|c|c|c|c|c|}
\hline \multirow[t]{2}{*}{ Cause of chronic renal failure } & \multicolumn{2}{|c|}{ Without ED } & \multicolumn{2}{|c|}{ With ED } & \multirow[t]{2}{*}{ P-values* } & \multirow[t]{2}{*}{ OR $(95 \% \mathrm{Cl})$} \\
\hline & $\mathrm{n}$ & $\%$ & $n$ & $\%$ & & \\
\hline \multicolumn{7}{|l|}{ Medication abuse } \\
\hline No & 91 & 93.8 & 202 & 97.1 & & \\
\hline Yes & 6 & 6.2 & 6 & 2.9 & 0.177 & $0.45(0.14-1.43)$ \\
\hline \multicolumn{7}{|l|}{ Diabetes Mellitus } \\
\hline No & 92 & 94.8 & 157 & 75.5 & & \\
\hline Yes & 5 & 5.2 & 51 & 24.5 & $<0.001$ & $5.98(2.30-15.51)$ \\
\hline \multicolumn{7}{|l|}{ Glomerulonephritis } \\
\hline No & 84 & 86.6 & 198 & 95.2 & & \\
\hline Yes & 13 & 13.4 & 10 & 4.8 & 0.011 & $3.06(1.29-7.26)$ \\
\hline \multicolumn{7}{|l|}{ Hypertension } \\
\hline No & 57 & 58.8 & 143 & 68.8 & & \\
\hline Yes & 40 & 41.2 & 65 & 31.3 & 0.088 & $1.54(0.94-2.54)$ \\
\hline \multicolumn{7}{|l|}{ Polycystic disease } \\
\hline No & 91 & 93.8 & 197 & 94.7 & & \\
\hline Yes & 6 & 6.2 & 11 & 5.3 & 0.751 & $0.85(0.30-2.36)$ \\
\hline \multicolumn{7}{|l|}{ Unknown ${ }^{\mathrm{a}}$} \\
\hline No & 75 & 77.3 & 155 & 74.5 & & \\
\hline Yes & 22 & 22.7 & 53 & 25.5 & 0.597 & $1.17(0.66-2.06)$ \\
\hline \multicolumn{7}{|l|}{ Others } \\
\hline No & 92 & 94.8 & 196 & 94.2 & & \\
\hline Yes & 5 & 5.2 & 12 & 5.8 & 0.828 & $1.13(0.39-3.29)$ \\
\hline Total & 97 & 100.0 & 208 & 100.0 & & \\
\hline
\end{tabular}

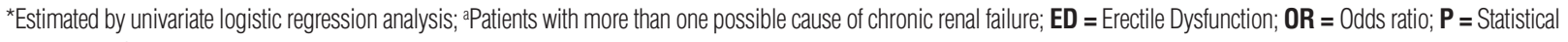
significance; $\mathbf{C l}=$ confidence interval.

coronary insufficiency increased the risk of ED in 5.24, 7.24 and 11.31 times respectively (Table-7). These three variables were those that had the greatest association with ED.

\section{DISCUSSION}

A high prevalence of $68.19 \%$ of ED in HD patients was found in our work. The prevalence of
ED in HD patients has a wide variability among studies (43 to $87.7 \%$ ) probably due to different methodologies and diagnostic criteria (5-13). The studies used different definitions and tools for ED assessment; some of them had low number of patients, were performed in a single-center evaluation and the populations evaluated differed from each other $(6-9,12,13)$. Despite the great variability of ED in HD patients the most recent studies 
Table 7 - Model of Multivariate Regression Logistic Analysis to identify factors independently associated with erectile dysfunction in hemodialysis patients.

\begin{tabular}{lcc}
\hline Factor & P-values $^{*}$ & OR (95\% Cl) \\
\hline Current use of alcohol & 0.006 & $3.25(1.41-7.51)$ \\
Educational level & 0.006 & $2.66(1.32-5.37)$ \\
Diabetes & 0.003 & $7.24(1.99-26.36)$ \\
Age & $<0.001$ & $5.24(2.61-10.49)$ \\
Calcium channel blockers & 0.037 & $2.26(1.05-4.84)$ \\
Coronary insufficiency & 0.025 & $11.31(1.35-94.54)$ \\
Years of use of alcohol (even if do not drink any more) & 0.036 & $2.28(1.06-4.90)$ \\
\hline
\end{tabular}

*Estimated by multivariate logistic regression analysis; $\mathbf{O R}=0$ dds ratio; $\mathbf{P}=$ Level of statistical significance; $\mathbf{9 5 \%} \mathbf{C l}=\mathbf{9 5 \%}$ confidence interval.

showed high prevalence. Severe ED rate of 42.95\% observed in our study is similar to results of previous researches that observed proportions ranging from 25.4 to $45.8 \%(6,7,10-12)$.

Similar to our results, several researchers showed association of ED with increased age of HD patients $(5-8,10-12,15,16)$. In the Massachusetts Male Aging Study (17) (2004), the prevalence of ED was strongly and independently associated with age. Despite this, the NIH Consensus Development Panel on Impotence (18) (1993) concluded that since other risk factors for ED appear with aging, ED could not be considered a direct result of aging. One of these age-related risk factors is the presence of atherosclerosis, which is also a known risk factor for ED (19). Atherosclerosis is responsible for the abnormal function and responsiveness of penile vasculature, and it can also contribute to the pathogenesis of ED (16).

There is no consensus about the impact of education status on ED. Although some studies showed no association between education level and ED (7,11), Moreira et al. (19) (2002) found that the education level is inversely correlated to ED and Johannes et al. (21) (2000) reported that the risk of developing age-related ED was higher in men with lower education degree. A possible reason is that poor education can be associated with low socioeconomic background. It is likely that people with lower education have more di- fficulty to health care access, so these people are subjected to higher rates of comorbidities associated with HD and/or less adequate treatment of uremia itself. Our data showed that independent of other factors, patients with lower education had more ED.

DM is the most common cause of CRF (15), and it is a risk factor for ED (17). As ED occurs in almost all diabetic patients with $\operatorname{CRF}(7,8)$ in our work, DM was also an independent risk factor of ED in male HD patients. Causes of ED in DM men are several: vascular disease (22), autonomic neuropathy, gonadal dysfunction, impaired neurogenic and endothelium mediated relaxation of penile smooth muscle $(23,24)$ and additionally HD $(6,7,10)$.

There is an association of ED and cardiovascular diseases (19). Endothelium dysfunction occurs in cardiovascular diseases and it may contribute to the pathogenesis of ED (25). The current study found an independent association between coronary insufficiency and ED.

In the present study, ED was positively and independently associated with current alcohol use and length of consumption of alcohol (past or current). Although individuals may be sexually disinhibited through the use of alcohol, clinical studies have shown that alcohol abuse causes irreversible damage to nerve endings in penis tissue, which is manifested as ED (26). 
Rosas et al. (10) (2001) found among HD patients that history of prostatic diseases was a statistically significant predictor of ED in unadjusted analyses. Lue (26) (2000) regards possible association of ED and benign prostatic hyperplasia (BPH), however, Stolic and Bukumiric (19) (2010) indicated that BPH did not constitute significant parameters among ED patients. In the present research, the association between ED and BPH was observed, however, not independently of other factors.

Several researches showed association between ED and cigarette use (27-29). This occurred because smoking causes vasoconstriction in the penile venous plexus and thereby affects contraction of cavernous smooth muscle, which has a negative effect on EF (26). Despite this, other studies did not find this association $(8,13,15,16,19)$. Association between ED and smoking habits (previous or current) not independent of other factors was found in this work.

Although high pre-dialysis creatinine levels significantly associated with sexual dysfunction are frequently reported $(5,30)$, Messina et al. (7) (2007) found that pre-dialysis creatinine levels were significantly lower in patients with ED. Our study showed association between lower creatinine levels and ED only on unadjusted analysis for confounding factors, as in Rosas et al. (10) (2001) study. The decreased creatinine levels in the ED patients may be a reflection of reduced muscle mass in older patients that are most likely to present ED.

No association of ED and PTH in HD patients has been verified in the present work and others $(9,11,19)$. However, Rosas et al. (10) (2001) found lower levels of PTH associated with ED only on unadjusted analysis for confounding factors. In small-scale, studies have been advocating that treatment of secondary hyperparathyroidism may result in significant improvement in sexual function in patients with CRF (31).

Patients with CRF usually do no present significant association between the use of antihypertensive drugs and ED $(8,10)$. On the other hand, in a revision research that lists the principal drugs used by the general population that are associated with ED, antihypertensive drugs were frequently found (32). In the current study it was found an independent association between ED and the use of calcium channel blockers. It is difficult, however, to determine whether the erectile impairment in controlled hypertension is due to the influence of the disease, medications, or both (10).

There are many considerations in this study that limit our findings. First, our sample size was relatively small, so this limits the possibility of detecting some interactions such as ED and obesity or hypertension. Second, this is a cross-sectional study, so it is just possible to establish association links between ED and risk factors without certainty of a causal relation between them. Third, this study did not assess variables that have been linked to ED, such as autonomic neuropathy, peripheral vascular disease, residual renal function and levels of testosterone, prolactin, zinc and thyroid hormones.

\section{CONCLUSIONS}

In summary, in this research, the HD men had high prevalence of ED and the main variables associated were higher age, current use of alcohol, long alcohol use (even for those who do not drink more), lower education level, DM (as cause of CRF), coronary insufficiency and use of channel blockers calcium.

\section{ABBREVIATIONS}
$\mathrm{BMI}=$ body mass index
$\mathrm{BPH}=$ benign prostatic hyperplasia
$\mathrm{CRF}=$ chronic renal failure
$\mathrm{DM}=$ Diabetes Mellitus
$\mathrm{ED}=$ erectile dysfunction
$\mathrm{EF}=$ erectile function
$\mathrm{HD}=$ hemodialysis
HDL $=$ high density lipids
IIEF = International Index of Erectile Function
$\mathrm{Kt} / \mathrm{V}=$ dialyzer clearance of urea $\mathrm{X}$ dialysis time/
volume of distribution of urea
LDL = low density lipids
MLRA = multivariable logistic regression analysis
$\mathrm{PTH}=$ parathormone
SD = standard deviation
SPSS = Statistical Package for the Social Sciences ULRA = univariate logistic regression analysis 


\section{CONFLICT OF INTEREST}

None declared.

\section{REFERENCES}

1. Makhlouf A, Kparker A, Niederberger CS:Depression and erectile dysfunction. Urol Clin North Am. 2007; 34: 565-74, vii.

2. Angulo J: Re: Erectile dysfunction in patients with chronic renal failure. Int Braz J Urol. 2007; 33: 845-6.

3. U S Renal Data System: USRDS 2012 Annual Data Report: Atlas of Chronic Kidney Disease and End-Stage Renal Disease in the United States, National Institutes of Health, National Institute of Diabetes and Digestive and Kidney Diseases; Bethesda, MD, 2012; vol. 1, chapter 3.

4. Rosas SE, Joffe M, Franklin E, Strom BL, Kotzker W, Brensinger $C$, et al.: Association of decreased quality of life and erectile dysfunction in hemodialysis patients. Kidney Int. 2003; 64: 232-8.

5. Malekmakan L, Shakeri S, Haghpanah S, Pakfetrat M, Sarvestani AS, Malekmakan A. Epidemiology of erectile dysfunction in hemodialysis patients using IIEF questionnaire. Saudi J Kidney Dis Transpl. 2011; 22: 232-6.

6. Makarem AR, Karami MY, Zekavat OR: Erectile dysfunction among hemodialysis patients. Int Urol Nephrol. 2011; 43: 117-23.

7. Messina LE, Claro JA, Nardozza A, Andrade E, Ortiz V, Srougi M: Erectile dysfunction in patients with chronic renal failure. Int Braz J Urol. 2007 ; 33: 673-8.

8. Cerqueira J, Moraes M, Glina S: Erectile dysfunction: prevalence and associated variables in patients with chronic renal failure. Int J Impot Res. 2002; 14: 65-71.

9. Toorians AW, Janssen E, Laan E, Gooren LJ, Giltay EJ, Oe PL, Donker AJ, Everaerd W: Chronic renal failure and sexual functioning: clinical status versus objectively assessed sexual response. Nephrol Dial Transplant. 1997; 12: 2654-63.

10. Rosas SE, Joffe M, Franklin E, Strom BL, Kotzker W, Brensinger $C$, et al.: Prevalence and determinants of erectile dysfunction in hemodialysis patients. Kidney Int. 2001; 59: 2259-66.

11. Neto AF, de Freitas Rodrigues MA, Saraiva Fittipaldi JA, Moreira ED Jr.: The epidemiology of erectile dysfunction and its correlates in men with chronic renal failure on hemodialysis in Londrina,southern Brazil. Int J Impot Res. 2002; 14 Suppl 2:S19-26.

12. Collaborative Depression and Sexual Dysfunction in Hemodialysis Working Group, Vecchio M, Palmer S, De Berardis G, Craig J, Johnson D, et al.: Prevalence and correlates of erectile dysfunction in men on chronic haemodialysis: a multinational cross-sectional study. Nephrol Dial Transplant. 2012 ; 27: 2479-88.
13. Seck SM, Dahaba M, Diouf B, Cisse MM, Gueye S, Ka EF, et al.: The burden of erectile dysfunction in dialysis patients in Senegal. Hemodial Int. 2011; 15: 280-3.

14. Rosen RC, Riley A, Wagner G, Osterloh IH, Kirkpatrick $J$, Mishra $A$ : The international index of erectile function (IIEF): a multidimensional scale for assessment of erectile dysfunction. Urology. 1997; 49: 822-30.

15. Naya Y, Soh J, Ochiai A, Mizutani Y, Ushijima S, Kamoi K, et al.: Significant decrease of the International Index of Erectile Function in male renal failure patients treated with hemodialysis. Int J Impot Res. 2002; 14: 172-7.

16. Ali ME, Abdel-Hafez HZ, Mahran AM, Mohamed HZ, Mohamed ER, El-Shazly AM, Gadallah AM, et al.: Erectile dysfunction in chronic renal failure patients undergoing hemodialysis in Egypt. Int J Impot Res. 2005; 17: 180-5. Erratum in: Int J Impot Res. 2005; 17: 390.

17. Feldman HA, Goldstein I, Hatzichristou DG, Krane RJ, McKinlay JB: Construction of a surrogate variable for impotence in the Massachusetts Male Aging Study. J Clin Epidemiol. 1994; 47: 457-67.

18. [No authors listed]: NIH Consensus Conference. Impotence. NIH Consensus Development Panel on Impotence. JAMA. 1993; 270: 83-90.

19. Stolic RV, Bukumiric ZM: Intima-media thickness of carotid arteries and erectile dysfunction in hemodialysis patients. Hemodial Int. 2010; 14: 510-4.

20. Moreira ED Jr, Lisboa Lôbo CF, Villa M, Nicolosi A, Glasser DB: Prevalence and correlates of erectile dysfunction in Salvador, northeastern Brazil: a population-based study. Int J Impot Res. 2002; 14 (Suppl 2): S3-9.

21. Johannes $C B$, Araujo AB, Feldman HA, Derby CA, Kleinman $\mathrm{KP}$, McKinlay JB: Incidence of erectile dysfunction in men 40 to 69 years old: Iongitudinal results from the Massachusetts male aging study. J Urol. 2000; 163: 460-3.

22. Jevtich MJ, Edson M, Jarman WD, Herrera HH: Vascular factor in erectile failure among diabetics. Urology. 1982; 19: 163-8.

23. Whitehead ED, Klyde BJ: Diabetes-related impotence in the elderly. Clin Geriatr Med. 1990; 6: 771-95.

24. Saenz de Tejada I, Goldstein I, Azadzoi K, Krane RJ, Cohen RA: Impaired neurogenic and endothelium-mediated relaxation of penile smooth muscle from diabetic men with impotence. N Engl J Med. 1989; 320: 1025-30.

25. Crowe LC, George WH:Alcohol and human sexuality: review and integration. Psychol Bull. 1989; 105: 374-86.

26. Lue TF: Erectile dysfunction. N Engl J Med. 2000; 342: 1802-13.

27. Feldman HA, Johannes $C B$, Derby CA, Kleinman KP, Mohr $B A$, Araujo $A B$, et al: Erectile dysfunction and coronary risk factors: prospective results from the Massachusetts male aging study. Prev Med. 2000; 30: 328-38. 
28. Derby CA, Mohr BA, Goldstein I, Feldman HA, Johannes CB, McKinlay JB: Modifiable risk factors and erectile dysfunction: can lifestyle changes modify risk? Urology. 2000; 56: 302-6.

29. Araujo AB, Johannes CB, Feldman HA, Derby CA, McKinlay JB: Relation between psychosocial risk factors and incident erectile dysfunction: prospective results from the MassachusettsMale Aging Study. Am J Epidemiol. 2000; 152: 533-41.

30. Soykan A, Boztas H, Kutlay S, Ince E, Nergizoglu G, Dileköz AY, et al.: Do sexual dysfunctions get better during dialysis? Results of a six-month prospective follow-up study from Turkey. Int J Impot Res. 2005; 17: 359-63.
31. Massry SG, Goldstein DA, Procci WR, Kletzky OA: Impotence in patients with uremia: a possible role for parathyroid hormone. Nephron. 1977; 19: 305-10.

32. Wein AJ, Van Arsdalen KN: Drug-induced male sexual dysfunction. Urol Clin North Am. 1988; 15: 23-31.

Correspondence address: Márcio Rodrigues Costa, MD Rua 15, número 87 / 802, Setor Oeste, Ed. Cotê D`or Goiânia, G0, 74140-035, Brazil Telephone: +55 62 3645-4664 E-mail: marciorodriguescosta@bol.com.br 